\title{
Issues in retrospective conversion
}

\author{
By C. Lee Jones \\ Program Consultant \\ Council on Library Resources
}

\section{Nine recommendations for a coordinated program to produce and share machine-readable bibliographic} records nationally.

$\mathbf{F}_{\mathrm{r}}$ ference Center in Wayzata, Minnesota, twentynine individuals focused their attention on a report, Issues in Retrospective Conversion, prepared by Jutta Reed-Scott, Dorothy Gregor, and Charles Payne. ${ }^{1}$ The underlying question during the conference was whether or not the cause of scholarship could be advanced by a carefully articulated program aimed at a coordinated approach to retrospective conversion of manual bibliographic records into machine-readable form by the research libraries of the country.

Support of scholarship and research is the fundamental objective of any retrospective conversion program. A requirement for providing that support is an openly accessible, consistent, logical national database of bibliographic records reflecting the nation's library resources. Throughout the conference it was clear that there are no national boundaries to scholarship and that in the shorter term, the recommendations of the conference and subsequent actions taken should include all North American interests, with a longer term goal of links to any bibliographic database in the world.

The conference discussions ranged broadly and the debate assured that a wide set of approaches and concerns were aired and became in some way a

\footnotetext{
${ }^{\mathrm{I}}$ This report is available for $\$ 3$ (prepaid only) from the Council on Library Resources, 1785 Massachusetts Avenue, N.W., Washington, DC 20036.
}

part of the recommendations which follow. While there may be alternative approaches to the problem, the following represents the sense of the group gathered at Spring Hill. Given the quality and extent of information available (in some cases more than adequate and in others frustratingly sketchy) these recommendations are the strongest statements that can be issued at this time. They suggest action on the part of the Association of Research Libraries as an organization and, less directly, on the part of every research library in the country.

\section{Recommendation 1}

A coordinated retrospective conversion ( $R E$ CON) program is a viable alternative at this time.

Whatever program results from these recommendations should not be viewed as a replacement for existing local RECON formats. The fundamental objective of such a program must be the conversion of manual records to machine-readable form and, secondarily, the upgrading of extant machine records that are less than full records.

This first recommendation flowed from the discussion of whether or not it made sense to mount such an organized effort at this time. Some argued that there was so much RECON going on that it would all be done in the next few years, despite the fact that there is no plan in place now and apparently much duplication of effort. The specific degree of duplication was not known, but suspected 
to be high. Since there are few if any RECON programs searching all shared cataloging service databases and none sharing records with all of them (OCLC, RLIN, WLN and LC), the argument was made that duplication was bound to be high.

A major question was what was meant by $\mathrm{RE}$ CON. In the context of this conference, RECON was limited to the original generation of machine records from older manual records. Thus, the nearly clerical tasks of identifying records in a database and attaching a holding symbol were deliberately excluded from any plan that might result. However, the process of identifying and upgrading to full record status any minimal record was considered to be an important contribution to the quality of resulting databases and so an important part of a national RECON plan.

\section{Recommendation 2}

North American research libraries are the focus of these recommendations and any program that may flow from them. However, this focus must also include the special resources of other institutions.

A principal reason for this focus is the present state of RECON in North America. Many smaller academic and public libraries have finished, embarked upon, or have near-term plans for the complete RECON of their collections. It was indicated that most collections of less than 250,000 volumes can be converted at reasonable institutional costs using the very large databases of one of the utilities or the services of a commercial vendor. A very high percentage of the RECON work will consist of matching records from the database and so require very little original RECON work. However, as collection size grows the costs of RECON become so large that it is difficult to devote sufficient institutional resources to accomplish a total RECON.

While there are few large research libraries that do not have some RECON activity either in process or scheduled, it is rare to find one intending to do all extant records because of the number of items requiring original $\mathrm{RECON}$ work and the very much higher costs associated with this process. In order to assist research libraries with their RECON loads, a coordinated program has a very good chance of distributing the amount of original RE$\mathrm{CON}$ work that any one institution would have to do.

There is no doubt that many smaller nonresearch libraries must do original RECON for some part of their collections. It is also probably true that there is not much local pressure on them to convert their special collections unless there is an institutional commitment to convert all records. For the most part, these libraries will have comparatively few unique records to add to a national database. Consequently, in order to expand the national database of RECON records for the benefit of scholars everywhere, it makes sense to focus the national coordinated RECON program on the re- search library community.

\section{Recommendation 3}

The Association of Research Libraries, probably through its Bibliographic Control Committee, should assume program definition and management oversight responsibilities.

There are several models for operation of such a

\section{ARL should assume}

\section{management oversight} responsibilities.

program within ARL including the microform clearinghouse and certain OMS operations. ARL should also invite the participation of a representative of IRLA (Independent Research Library Association) during the program definition stages of the process. Early attention needs to be paid to the exact scope of the RECON problem.

Since most of the RECON problem that remains to be solved, at least in terms of original RECON, is located within research libraries, it is reasonable to suggest that ARL should take the organizational lead in defining what should be done and the strategy that should be used. These recommendations will be forwarded to ARL as soon as possible for their action.

Not all research libraries are members of ARL; several are members of IRLA. To make certain that non-ARL member research libraries are part of the program and are urged to contribute to the end result, they should be invited to participate in the Bibliographic Control Committee. There will be other collections that should be a part of the program that are not represented by these two organizations, and their interests should also be accounted for in the definition of the program.

While the Bibliographic Control Committee cannot be expected to manage the program, there are models within ARL that might be used to pattern the RECON program. The microform clearinghouse effort and certain OMS operations should be examined in order to determine the best way to handle the daily management requirements of a program designed to coordinate RECON activities within the research library community.

The precise scope of the original RECON problem is unknown. A modest and rapidly mounted effort should be made to determine the size of the problem and some indication of how it should be approached. Are there concentrations of records that need to be converted? Is the problem tractable? 


\section{Recommendation 4}

A coordination program for RECON must capitalize fully upon other RECON record-producing activities.

There are several projects that are already underway that are creating what amount to RECON records as by-products of their activities. These include the NEH-funded newspaper project, the major microform set project, RLG's RECON project, and certain preservation projects. Each of these projects produces bibliographic records which either replace existing manual records or upgrade incomplete machine form records. It is possible to identify the groups of materials that are being dealt with in these projects and any RECON program must do so in order to avoid or minimize duplicate record production. By recognizing the contributions expected from these ongoing activities, the ARL plan for coordinated RECON work will include these projects and so expand the productivity that can be expected from it.

\section{Recommendation 5}

The approach recommended is to segregate the work by subject based upon the LC classification scheme, or, under certain conditions, based upon certain very strong special collections.

Two programs were identified as being useful in identifying institutional strengths based upon subjects as defined by the LC classification scheme: the National Collection Inventory Project (NCIP) and the National Shelflist Count (NSC). Since the former is still in its early stages of operation, it is more likely that the NSC will prove to be more useful in the short run despite certain limitations. While LC information is part of the NSC data, only 25 other libraries are included in this 1977 compilation. NSC can yield initial information on size of research collection, while NCIP will eventually yield collection quality data.

\section{Recommendation 6}

It is important that any institution choosing to participate in the coordinated RECON program must agree to produce and share records according to a set of agreed upon standards.

Those standards are based upon the premise that the fullest possible record properly encoded is to be preferred. Specific standards that should be followed include:

1. MARC format for data encoding and exchange.

2. The National Level Bibliographic RecordMinimal Level Record standard is the least acceptable record.

3. AACR2 is preferred for access points.

4. Subject headings should be LCSH/MeSH compatible.

There is no point in putting together a program for coordinated RECON unless the resulting records can be shared. Sharing records requires an agreed upon set of standards and distribution among the database of the large shared cataloging services and other suppliers of bibliographic records. In the end, these databases are the component parts of our objective, a logical, consistent national bibliographic database openly available to all citizens.

The use of MARC for the exchange of data is assumed.

The specification of the Minimal Level Record as the least acceptable standard is intended to specify the absolute minimum and not to specify the target against which to measure quality. In fact, if support is provided in the context of the program for the production of RECON original records, little or no support should be provided for the production of minimal records. Any minimal record that is selected by another institution may force that institution to do additional work if it chooses to use only full records in its database. The object of the program is to do as many original RECON records as possible and do them fully once so that others may share them without undue additional work.

There is also a need to keep the costs of RECON under control. Specifying AACR2 as preferred for access points is a case in point. Should all access points and descriptions be required to be consistent with AACR2, few if any institutions could afford the time required to bring old records up to the new standard. This would amount to recataloging and not just converting from a manual to a machine record. It would be possible to convert headings by running them against an AACR2 authority file and dealing only with those that do not match.

Where subject headings are used in a RECON record they should be consistent with the two largest controlled subject heading lists, the Library of Congress Subject Headings and the National Library of Medicine's Medical Subject Headings. It was agreed that subjects will be important even for the older records, and that an effort to assure consistency with the two prime subject heading standards was required for the benefit of users.

\section{Recommendation 7}

The telecommunication protocols resulting from the Linked Systems Project should provide the enabling mechanism for the sharing of records produced on the several shared cataloging services'systems.

The linking protocols that are now in the testing phase and approaching the implementation stages are viewed as the appropriate mechanisms for making resulting and other records available to the library user community. It is realized that this will take some time to implement, but it should remain the objective of the library community.

\section{Recommendation 8}

When the Linked Systems Project is fully opera- 
tional, access to records will be diametrically enhanced. However, access to all original or upgraded records resulting from a coordinated RECON program should be provided through an LC distribution mechanism. Any LC records input by another organization according to certain guidelines specified by LC could be accepted as LC MARC records, and so, distributed as part of the MARC Distribution Service, and maintained by the Library of Congress. The Library of Congress agreed to investigate the possibility of an LC distribution mechanism.

Participants recognized that the widest possible distribution would come from using an LC distribution mechanism. All subscribers would receive the records and there are no limits, other than financial, to those who may subscribe. The commercial sector will thus be served as readily as the notfor-profit sector. It would be particularly desirable to have the $\mathrm{LC}$ cataloging records included in the MARC Distribution Service where they would be part of a continuing maintenance program.

\section{Recommendation 9}

The ARL Bibliographic Control Committee should explore a variety of funding operations for the support of a coordinated RECON program.

Individual projects should be packaged for fundraising purposes. In addition, a strategy of assessments of research libraries should be explored. Finally, appropriate staff from Title II-C and NEH should be advised that a coordinated RECON program is being prepared.

RECON activities have received sporadic support for several years. Much has been done with local funding in efforts to implement online circulation systems that required more or less full bibliographic records as raw material, and there is bound to be more local support of RECON in the years to come. A national coordinated strategy for retrospective conversion, whether fully or partially funded or not, would provide the context in which institutions could approach their own RECON projects, knowing that they would be making up a contribution to the national RECON effort. Thus, a worst case of no extramural support for RECON still calls for a logical, coordinated RECON plan.

There are, however, many foundations which may be interested in specific pieces of the RECON problem. It would be useful, for example, to put together a package that might be interesting to the Getty Foundation in the area of art and architecture. Other foundations may be interested in other pieces of the knowledge spectrum. It would not be terribly difficult, once data was examined from the NSIP, to put together some subject assignment suggestions for a limited number of institutions, to secure their commitment to the concept, and to seek support for a special package of materials. The nature of the support should be such that each participating institution is investing in the project rather substantially. Foundations are more likely to be in- terested in providing matching funds than they are in supporting all the institution's costs relative to RECON. Support should be sought within these limitations.

In a more broadly based program for generating support for RECON, ARL should consider a program of assessments of research libraries in order to accumulate resources that could be used as match-

\section{Objective: A national database openly available to all citizens.}

ing funds for the RECON effort. Some institutions will be able to make cash payments to a projectspecific fund. Others will not be able to do much more than to allocate a specific sum within their operating budgets as matching support for RECON. These non-cash commitments are likely to be in the form of staff and other resources and should be viewed as an acceptable alternative to cash commitments. Again, such a resource pool may attract matching attention from the foundation and federal funding communities.

Both Title II-C and NEH have funded RECON projects in a less than coordinated way over the past several years. Both agencies should be alerted to the fact that there is now an effort to produce a logical coordinated plan for RECON activities. Alerting these two programs to what is coming should allow them to capitalize upon the plan in their support of RECON proposals.

The foregoing constitute the central recommendations of the three-day conference. As one might expect, there were many other recommendations that did not receive such wide support or which had poor specific fits in the program recommended above. The most useful of these recommendations are summarized as miscellanous recommendations.

\section{Miscellanous recommendations}

Optical Character Recognition (OCR) techniques should be explored in light of some new developments in the field. Given that most of RECON is the capture of data that already exists in a variety of print formats and that there have been some interesting recent developments in OCR and the controlling software, a renewed examination of OCR technology for purposes of supporting RECON should be undertaken. The Council on $\mathrm{Li}$ brary Resources has committed itself to such an appraisal.

One of the products of the RECON program will 
be the conversion of records that were originally the product of LC cataloging. It was suggested that all of these records should be flagged and sent to LC by the shared cataloging services as a service to LC. LC representatives agreed to consider the usefulness to LC of this suggestion.

While the Linked Systems Project will result in operating links between the Library of Congress, the Research Libraries Group, and the Washington Library Network, it will be some time before OCLC can become a part of the technical link. Microenhancer or similar techniques using microcomputers should be developed for searching several databases in the RECON process. Since one of the objectives is to reduce duplicative effort, it makes no sense to search only one database when there is some likelihood that similar work may already have been done on one or more others. This suggestion may require more software work on the part of the target databases than they are willing to do, but there was encouragement to explore this avenue as a short-term solution to the lack of operational links among the utilities.

These recommendations form the essence of a nationally coordinated program for retrospective conversion of print form bibliographic records. It is a program that has the chance of reducing the aggregate costs of the RECON process and securing funding for making a very large dent in the inventory of records that need to be converted to machine-readable form in order to better support the work of the scholarly community.

Editor's note: No copyright is claimed on this article, which the author wrote as part of his official duties as an employee of the U.S. government.

\title{
Managing automation for results:
}

\section{Completing tasks while participative}

\section{planning proceeds}

\author{
By Ellen G. Miller \\ Director, Library Systems Development \\ University of Cincinnati
}

\section{Planning for automation with the end-user in mind.}

For many university and research libraries, the
lapsed time between starting library automation
planning and securing final top management
budget signatures is several months. Perhaps it
even takes years. The competition in higher educa-
tion for scarce resources means that library auto-
mation managers and CEO librarians must create
a careful case for library automation. One method
for creating that case, time-consuming but politi-
cally and psychologically helpful, is participative

planning.

As used in this article, participative planning goes beyond the recent library literature concerning participative management ${ }^{1}$ because it specifi-

${ }^{1}$ For a useful summary, see Nicholas C. Burckel, "Participatory Management in Academic Libraries: A Review," College and Research Libraries 45(January 1984):25-34. 